\title{
Occurrence and Antimicrobial Resistance of Pathogenic Vibrios Isolated from Green Mussel, Perna viridis L. 1758 in Bacoor Bay, Cavite, Philippines
}

\author{
Norbel A. Tabo, ${ }^{1,2}$ Vivian B. Ramirez, ${ }^{2}$ Hazel Anne L. Tabo ${ }^{2}$ and Nina G. Gloriani ${ }^{1}$ \\ ${ }^{1}$ Medical Microbiology Department, College of Public Health, University of the Philippines-Manila \\ ${ }^{2}$ Biological Sciences Department, College of Science, De La Salle University-Dasmariñas, Cavite
}

\begin{abstract}
Objective. To determine the occurrence and antimicrobial resistance of pathogenic vibrios from green mussel, Perna viridis in Bacoor Bay, Cavite.

Methods. Vibrios were isolated using TCBS agar and confirmed using API Identification kit. The relationship between the density of vibrios and environmental parameters such as months, harvest sites and other physico-chemical parameters of water was determined. The isolated vibrios were subjected to antibiotic resistance testing to determine the resistance patterns.

Results. Pathogenic vibrios were isolated in all of the 90 mussel samples. Of the 183 vibrio isolates, 75 strains were $V$. alginolyticus and 53 strains belonged to $V$. cholerae wherein 18 (34\%) of these were $V$. cholerae serotype O1. Forty nine (49) strains belonged to $V$. parahaemolyticus and six were $V$. vulnificus. Using the regression analysis, salinity, water temperature and $\mathrm{pH}$ have significant correlation on the density of vibrios $(p=0.0309)$ with regression model, total vibrios $=-16990763+145858$ Salinity + 186808 Temperature $+1037886 \mathrm{pH}$. In the antimicrobial resistance assay, ampicillin had the highest drug resistance (37.8\%) followed by nalidixic acid (10.4\%), tetracycline $(10.4 \%)$ and co-trimoxazole (9.3\%).
\end{abstract}

Conclusion. Pathogenic vibrios were isolated in mussels of Bacoor, Cavite and can be predicted using salinity, temperature and $\mathrm{pH}$ of the water. Thirty six percent $(36 \%)$ of Vibrio isolates were resistant to ampicillin.

Key Words: antimicrobial susceptibility pattern, occurrence, pathogenic vibrios \footnotetext{
Center, Pasig City.

Corresponding author: Norbel A. Tabo DLSU-D, DBB-B, Dasmariñas City, Cavite

Telephone: +6346 4164531

Fax Number: +6346 4164524

Email: natabo@dlsud.edu.ph
}

Presented at the 4th Philippine National Health Research SystemConvergence in Divergence, August 10-11, 2010, Crowne Plaza, Ortigas

\section{Introduction}

Pathogenic vibrios are primarily involved in causing gastrointestinal illnesses, wound infection and bacteremia in humans. ${ }^{1}$ In the Philippines, acute watery diarrhea, which is the primary sign for gastrointestinal infections, is the fifth leading cause of morbidity and third in Cavite-LagunaBatangas-Rizal-Quezon (CALABARZON) area. ${ }^{2}$ Infections arise due to the consumption of raw, undercooked, or improperly processed shellfishes or other seafoods containing significant levels of bacteria. Many seafoodassociated disease outbreaks have been reported worldwide including the Philippines, and vibrios are considered to be the major bacterial cause of these identifiable illnesses. ${ }^{3,4}$

The coastal waters of Bacoor Bay support a diverse aquatic biota and a robust mussel and oyster industry. However, this environment also provides suitable conditions for the growth of pathogenic bacteria particularly vibrios that pose problems to human health. In marine waters, shellfishes concentrate microorganisms during the filterfeeding process. Consequently, filter feeders are recognized as reservoirs for various microbial pathogens including Vibrio spp. However, the form of vibrio shed from infected humans is somewhat fragile and cannot survive long in marine environment. Hence, it is suggested that dormant stages exist to allow long term survival in saltwater environments ${ }^{5}$ and further infect the people within the coastal areas.

Traditionally, vibrio is considered highly susceptible to all antimicrobials. ${ }^{6}$ However, during the past few decades, antimicrobial resistance had emerged and evolved in many bacterial genera due to the excessive use of antimicrobials in human and agricultural systems. ${ }^{7}$ Tetracycline is the empiric drug of choice, but studies have shown that resistant strains are becoming prominent. ${ }^{8,9}$ In the Philippines, strains with transferrable multiple drug resistance genes were already isolated ${ }^{10}$ and in some endemic areas, tetracycline-resistant $V$. cholerae had emerged wherein the genes are carried by transmissible plasmids. ${ }^{10}$ Vibrio infection is treatable by oral rehydration and/or intravenous fluid therapy, ${ }^{11}$ but when epidemics occur, the administration of antibiotics during the acute phase of the disease may reduce the severity and level of suffering by reducing the amount of purging and the length of time that the bacterium is shed. ${ }^{12}$ This study aimed 
to: (1) determine the occurrence of pathogenic vibrios in green mussel, Perna viridis L. 1758; (2) correlate the total vibrios isolated from green mussel in relation to sampling period, harvest site, conductivity, water temperature, salinity, and $\mathrm{pH}$; and (3) provide an update on the level of resistance of the isolated pathogenic vibrios on selected antimicrobial agents.

\section{Methods}

Sampling Sites. Bacoor Bay is a large inlet of southeastern Manila Bay and one of the shellfish-farming sites in Cavite province. It is also the major source of mussels, oysters and crustaceans for the nearby municipalities. On the average, one hundred sacks of mussels are harvested every day in Brgy. Sineguelasan, accounting to P 15,000.00 per day based on personal communication with the shellfish farm owners. Mussels were obtained from shellfish beds in three harvest sites located in Bacoor Bay, Cavite (Figure 1). Five samples per site were obtained with 10 pcs of mussels per sample. The shellfish beds were made up of bamboos stacked in parallel with each other. The samples were collected every $10^{\text {th }}$ to $15^{\text {th }}$ of the month and between 9:00 AM to 12:00 N from July 2009 to December 2009 since acute watery diarrhea and cholera during these months increase dramatically. Salinity, conductivity, and temperature were measured directly using Salinity-Conductivity-Temperature (SCT) meter (YSI EC 300) while $\mathrm{pH}$ was measured with a $\mathrm{pH}$ meter (Orion 210A).

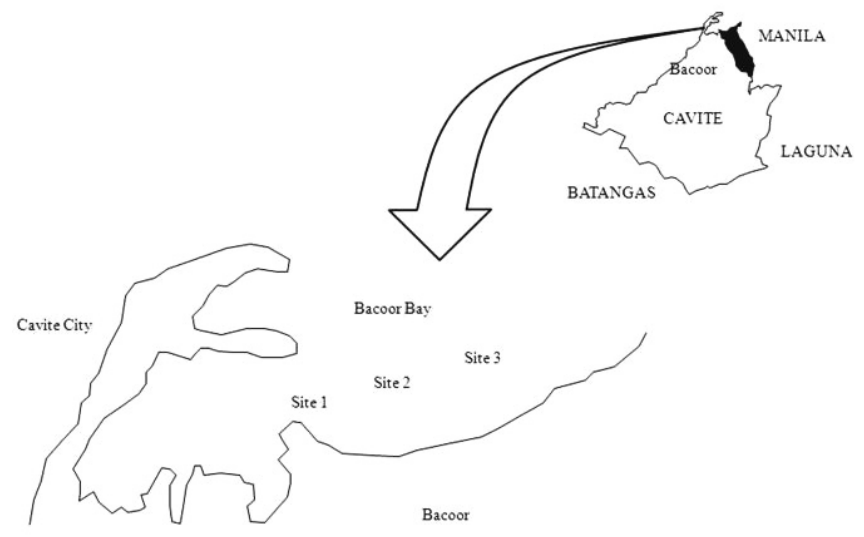

Figure 1. Sampling sites where mussels were collected for the analysis of pathogenic vibrios (longitude and latitude; Site 1: $120^{\circ} 55^{\prime} 26.56^{\prime \prime} \mathrm{E} 14^{\circ} 28^{\prime} 25.95^{\prime \prime} \mathrm{N}$; Site 2: $120^{\circ} 56^{\prime} 25.89^{\prime \prime} \mathrm{E}$ $14^{\circ} 28^{\prime} 19.63^{\prime \prime} \mathrm{N}$; Site 3: $\left.120^{\circ} 57^{\prime \prime} 18.74^{\prime \prime} \mathrm{E} 14^{\circ} 28^{\prime} 20.13^{\prime \prime} \mathrm{N}\right)$.

Sample Collection and Enrichment. Sample preparation was done according to the methods described. ${ }^{13}$ From the sampling sites, the mussels were placed in an ice chest and transported to the Biological Sciences Department Research Laboratory (BSDRL) of De La Salle University-Dasmariñas (DLSU-D). They were scrubbed under running water to remove debris and were opened aseptically using a sterilized spatula. Ten grams of mussel meat were homogenized in $90 \mathrm{~mL}$ alkaline peptone water (APW) for 1 min and incubated at $37^{\circ} \mathrm{C}$ for $18 \mathrm{~h}$.

Determination of Total Vibrios. After $18 \mathrm{~h}$ of incubation at $37^{\circ} \mathrm{C}$, tenfold serial dilution up to $10^{-4}$ was prepared using phosphate buffer solution (PBS) as diluent. Dilutions from $10^{-2}$ to $10^{-4}$ were spread plated into thiosulfate citrate bile sucrose (TCBS) agar in triplicates. The plates were incubated at $37^{\circ} \mathrm{C}$ for $24 \mathrm{~h}$. Colony forming units per gram $(\mathrm{cfu} / \mathrm{g})$ of sample for the total vibrios were determined.

Isolation, Screening and Confirmation of Pathogenic Vibrios. Colonies from the TCBS were characterized based on colony size, elevation, surface, and pigmentation. Typical colonies resembling $V$. alginolyticus, $V$. cholerae, $V$. parahaemolyticus and $V$. vulnificus were purified and maintained in brain heart infusion agar (BHIA). In the screening of isolated vibrios, cultures in $0,3,6,8$ and $10 \%$ $\mathrm{NaCl}$ in nutrient agar (NA), oxidase test, and VogesProskauer test were performed. In the confirmation of Vibrio spp., serologic agglutination tests and beta-hemolysis were performed followed by the use of $\mathrm{API} \circledast$ Identification Kit 20E (BioMerieux®). In serological test, a $20 \mu \mathrm{L}$ of polyvalent $\mathrm{V}$. cholerae O1 antiserum (Difco) was mixed with an emulsified culture. A positive reaction was indicated by a rapid, strong agglutination in a clear background. In hemolysis test, the isolates were streaked in blood agar plates and incubated at $37^{\circ} \mathrm{C}$ for $24 \mathrm{~h}$. A positive reaction was indicated by a hemolysis. Lastly, the API profiles for the isolates were analyzed using APILAB Manual.

Antibiotic Resistance of Pathogenic Vibrios. The isolated pathogenic vibrios were grown in brain heart infusion broth (BHI-Difco) for $24 \mathrm{~h}$. After $24 \mathrm{~h}$, the bacterial suspensions were centrifuged at 3,000 rpm for $1 \mathrm{~min}$. The pellet was resuspended in sterile PBS and the turbidity was adjusted to $0.5 \mathrm{McF}$ arland standard. A cotton pledget was dipped into the suspension and swabbed in Mueller-Hinton agar (MHA) plate. The antibiotic discs with concentration of the drug per disc as stated in parentheses were used: ampicillin $(10 \mu \mathrm{g})$, chloramphenicol $(30 \mu \mathrm{g})$, ciprofloxacin (5 $\mu \mathrm{g})$, co-trimoxazole $(25 \mu \mathrm{g})$, gentamicin $(10 \mu \mathrm{g})$, nalidixic acid $(30 \mu \mathrm{g})$, neomycin $(30 \mu \mathrm{g})$, norfloxacin $(10 \mu \mathrm{g})$, streptomycin $(10 \mu \mathrm{g})$ and tetracycline $(30 \mu \mathrm{g})$ (Mastdiscs $^{\mathrm{TM}}$, Mast Diagnostics, Merseyside, UK). The plates were incubated at $37^{\circ} \mathrm{C}$ for $18 \mathrm{~h}$. After incubation, the zones of inhibition were measured and interpreted using Clinical and Laboratory Standards Institute guide. ${ }^{14}$ The control strains of Escherichia coli ATCC 25922 and Vibrio cholerae ATCC 9459 were used.

Statistical Analyses. The relationship between total vibrios and predictor variables such as sampling months, harvest sites, salinity, conductivity, water temperature, and $\mathrm{pH}$ was investigated using multiple regression analysis. A model was built using a stepwise backward elimination procedure. Student's independent t-test was used to 
determine the difference in environmental parameters during the 6 month-period. All statistical analyses were conducted using STATA 9.0 for Windows (STATA Corp., College Station, Texas 77845 USA). Significance was defined as a probability of less than $0.05(p<0.05)$.

\section{Results}

\section{Density of the total vibrios in relation to environmental parameters}

The average density of the total vibrios in relation to sampling month, salinity, conductivity, water temperature, and $\mathrm{pH}$ is shown in Figure 2. During the six-month sampling period, the density of vibrios increased significantly from July to August $(p=0.0001)$ and then decreased until September. A significant increase $(p=0.0001)$ from September to December was also observed. In salinity, there was a significant decrease $(p=0.0001)$ from July to September and then increased until December $(p=0.000)$. In conductivity, a significant decrease $(p=0.001)$ from July to October was observed and then increased significantly until December $(p=0.0001)$. In water temperature, a significant increase $(p=0.0001)$ from July to September was observed and then decreased until December $(p=0.0001)$. The $\mathrm{pH}$ also showed an increasing trend from July to October $(p=0.0001)$ and decreased until December $(p=0.0001)$. Using the multiple regression analysis, it was found out that salinity, water temperature and $\mathrm{pH}$ had significant effect on the density of vibrios $(\mathrm{r}=0.68 ; p=0.0309)$. The linear regression model that best fits the data is total vibrios $=-16990763+145858$ Salinity +186808 Temperature $+1037886 \mathrm{pH}$. The main finding from the model was a steep increase in the probability of finding the vibrios when these three environmental parameters increased. The model had an $\mathrm{R}^{2}$ of 0.4617 , indicating that $46.17 \%$ of the observed variation in total vibrios was attributed to the differences in salinity, water temperature and $\mathrm{pH}$.

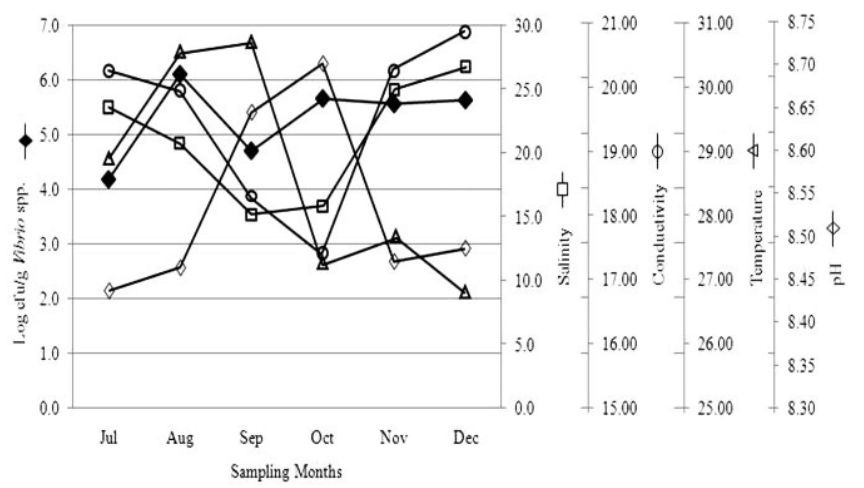

Figure 2. Average density of Vibrio spp. in relation to sampling month, salinity, conductivity, water temperature, and $\mathrm{pH}$.

\section{Occurrence of pathogenic vibrios in mussels from six-month sampling period}

Vibrios were isolated from all 90 mussel samples in shellfish beds of Bacoor Bay, Cavite. The isolation of pathogenic vibrios was accomplished by employing direct culture in APW enrichment followed by selective culture to TCBS. Salt tolerance and selective biochemical tests were used to differentiate pathogenic vibrios. Table 1 shows the presumptive identification of the isolates. Two hundred seventy (270) isolates were subjected to selected biochemical tests. Of these, 75 isolates were presumed as $V$. alginolyticus using the $10 \% \mathrm{NaCl}$ and Voges-Proskauer test, 53 isolates were presumed as $V$. cholerae using the $3 \% \mathrm{NaCl}, 49$ isolates were presumed as $V$. parahaemolyticus using the $8 \% \mathrm{NaCl}$ and hemolysis test and 6 isolates were presumed as $V$. vulnificus using $8 \% \mathrm{NaCl}$ test with a total of $183(67.8 \%)$ isolates.

Table 1. Presumptive identification of pathogenic vibrios in green mussel, Perna viridis L. 1758.

\begin{tabular}{|c|c|c|c|c|}
\hline \multirow[b]{2}{*}{ Tests } & \multicolumn{4}{|c|}{ Number of Positive Strains (\%) } \\
\hline & $\begin{array}{c}\text { Vibrio } \\
\text { alginolyticus } \\
\mathrm{n}=81\end{array}$ & $\begin{array}{c}\text { Vibrio } \\
\text { cholerae } \\
\mathrm{n}=53\end{array}$ & $\begin{array}{c}\text { Vibrio } \\
\text { parahaemolyticus } \\
\mathrm{n}=51\end{array}$ & $\begin{array}{l}\text { Other } \\
\text { vibrios } \\
\mathrm{n}=85\end{array}$ \\
\hline Oxidase test & $81(100 \%)$ & $53(100 \%)$ & $51(100 \%)$ & $85(100 \%)$ \\
\hline Fermentation of Sucrose & $80(99 \%)$ & $53(100 \%)$ & $0(0 \%)$ & $79(93 \%)$ \\
\hline Colony size in TCBS & $>5 \mathrm{~mm}$ & $2-4 \mathrm{~mm}$ & $2-3 \mathrm{~mm}$ & variable \\
\hline Colony elevation in TCBS & convex & flat & flat & variable \\
\hline Colony surface in TCBS & smooth & smooth & smooth & variable \\
\hline \multicolumn{5}{|l|}{ Growth in: } \\
\hline $0 \% \mathrm{NaCl}$ & $0(0 \%)$ & $53(100 \%)$ & $0(0 \%)$ & $0(0 \%)$ \\
\hline $3 \% \mathrm{NaCl}$ & $81(100 \%)$ & $53(100 \%)$ & $51(100 \%)$ & $85(100 \%)$ \\
\hline $6 \% \mathrm{NaCl}$ & $78(96 \%)$ & $0(0 \%)$ & $50(98 \%)$ & $15(18 \%)$ \\
\hline $8 \% \mathrm{NaCl}$ & $77(95 \%)$ & $0(0 \%)$ & $49(96 \%)$ & $6(7 \%)$ \\
\hline $10 \% \mathrm{NaCl}$ & $75(93 \%)$ & $0(0 \%)$ & $0(0 \%)$ & $0(0 \%)$ \\
\hline Hemolysis & ND & ND & $49(96 \%)$ & ND \\
\hline Voges-Proskauer test & $80(99 \%)$ & $45(85 \%)$ & $0(0 \%)$ & $0(0 \%)$ \\
\hline V. cholerae $\mathrm{O} 1$ antiserum & ND & $18(34 \%)$ & ND & ND \\
\hline
\end{tabular}


Table 2. Antibiotic susceptibility patterns of the isolated pathogenic vibrios.

\begin{tabular}{|c|c|c|c|c|c|c|c|c|c|c|}
\hline \multirow{2}{*}{ Antibiotic tested $(\mu \mathrm{g})$} & \multicolumn{5}{|c|}{ Number of resistant strains (\%) } & \multicolumn{5}{|c|}{ Number of susceptible strains (\%) } \\
\hline & VA & VC & VP & VV & Total & VA & VC & VP & VV & Total \\
\hline Ampicillin & 41 & 31 & 27 & 0 & 99 & 26 & 18 & 21 & 6 & 71 \\
\hline$(10 \mu \mathrm{g})$ & $55 \%$ & $58 \%$ & $55 \%$ & $0 \%$ & $36.70 \%$ & $35 \%$ & $34 \%$ & $43 \%$ & $100 \%$ & $26.30 \%$ \\
\hline Chloramphenicol & 3 & 3 & 2 & 0 & 8 & 63 & 38 & 41 & 6 & 148 \\
\hline$(30 \mu \mathrm{g})$ & $4 \%$ & $6 \%$ & $4 \%$ & $0 \%$ & $3.00 \%$ & $84 \%$ & $72 \%$ & $84 \%$ & $100 \%$ & $54.80 \%$ \\
\hline Ciprofloxacin & 3 & 1 & 0 & 0 & 4 & 72 & 49 & 49 & 6 & 176 \\
\hline$(5 \mu \mathrm{g})$ & $4 \%$ & $2 \%$ & $0 \%$ & $0 \%$ & $1.50 \%$ & $96 \%$ & $92 \%$ & $100 \%$ & $100 \%$ & $65.20 \%$ \\
\hline Co-trimoxazole & 6 & 10 & 6 & 0 & 22 & 66 & 39 & 43 & 6 & 154 \\
\hline$(25 \mu \mathrm{g})$ & $8 \%$ & $19 \%$ & $12 \%$ & $0 \%$ & $8.10 \%$ & $88 \%$ & $74 \%$ & $88 \%$ & $100 \%$ & $57.00 \%$ \\
\hline Gentamicin & 2 & 0 & 0 & 0 & 2 & 73 & 53 & 49 & 6 & 181 \\
\hline$(10 \mu \mathrm{g})$ & $3 \%$ & $0 \%$ & $0 \%$ & $0 \%$ & $0.70 \%$ & $97 \%$ & $100 \%$ & $100 \%$ & $100 \%$ & $67.00 \%$ \\
\hline Neomycin & 0 & 0 & 1 & 0 & 1 & 66 & 48 & 44 & 6 & 164 \\
\hline$(30 \mu \mathrm{g})$ & $0 \%$ & $0 \%$ & $2 \%$ & $0 \%$ & $0.40 \%$ & $88 \%$ & $91 \%$ & $90 \%$ & $100 \%$ & $60.70 \%$ \\
\hline Nalidixic acid & 12 & 11 & 2 & 0 & 25 & 45 & 26 & 45 & 6 & 122 \\
\hline$(30 \mu \mathrm{g})$ & $16 \%$ & $21 \%$ & $4 \%$ & $0 \%$ & $9.30 \%$ & $60 \%$ & $49 \%$ & $92 \%$ & $100 \%$ & $45.20 \%$ \\
\hline Norfloxacin & 0 & 0 & 0 & 0 & 0 & 75 & 50 & 49 & 6 & 180 \\
\hline$(10 \mu \mathrm{g})$ & $0 \%$ & $0 \%$ & $0 \%$ & $0 \%$ & $0.00 \%$ & $100 \%$ & $94 \%$ & $100 \%$ & $100 \%$ & $66.70 \%$ \\
\hline Streptomycin & 2 & 1 & 2 & 0 & 5 & 62 & 43 & 41 & 6 & 152 \\
\hline$(10 \mu \mathrm{g})$ & $3 \%$ & $2 \%$ & $4 \%$ & $0 \%$ & $1.90 \%$ & $83 \%$ & $81 \%$ & $84 \%$ & $100 \%$ & $56.30 \%$ \\
\hline Tetracyline & 7 & 11 & 7 & 0 & 25 & 61 & 37 & 41 & 6 & 145 \\
\hline$(30 \mu \mathrm{g})$ & $9 \%$ & $21 \%$ & $14 \%$ & $0 \%$ & $9.30 \%$ & $81 \%$ & $70 \%$ & $84 \%$ & $100 \%$ & $53.70 \%$ \\
\hline
\end{tabular}

VA - V. alginolyticus; VC - V. cholerae; VP - V. parahaemolyticus; VV - V. vulnificus

\section{Antimicrobial Resistance of the isolated pathogenic vibrios}

The 183 isolates were subjected to 10 antibiotics (Table

2). The results showed that the isolated pathogenic vibrios were resistant to ampicillin $(36.7 \%)$ followed by nalidixic acid $(9.3 \%)$, tetracycline $(9.3 \%)$ and co-trimoxazole $(8.1 \%)$. None of the isolates had drug resistance to norfloxacin. However, only 1 isolate was resistant to neomycin. On the other hand, most of the isolates were sensitive to gentamycin $(67.0 \%)$, norfloxacin $(66.7 \%)$, and ciprofloxacin (65.2\%). All strains of $V$. vulnificus were susceptible to ten antibiotics used. In the analysis of multidrug resistance, 13 (16\%) $V$. alginolyticus, $16(30 \%) \quad V$. cholerae and 7 (14\%) $\quad V$. parahaemolyticus isolates were found to be resistant to at least 2 drugs (Table 3). In the antimicrobial resistance profile, 2 strains of $V$. alginolyticus and 1 strain of $V$. parahaemolyticus were resistant to 5 drugs, namely ampicillin, nalidixic acid, co-trimoxazole, ciprofloxacin, and streptomycin (AP-NA-TSCIP-S), ampicillin, nalidixic acid, co-trimoxazole, tetracycline, and chloramphenicol (AP-NA-TS-T-C) and neomycin, nalidixic acid, co-trimoxazole, tetracycline, and chloramphenicol (NE-NA-TS-T-S), respectively. Two (2) strains of $V$. alginolyticus were resistant to 4 drugs ampicillin, nalidixic acid, co-trimoxazole, chloramphenicol (AP-NA-TSC) and ampicillin, nalidixic acid, tetracycline, chloramphenicol (AP-NA-T-C) whereas $1 \mathrm{~V}$. cholerae strain was resistant to 4 drugs ampicillin, nalidixic acid, Cotrimoxazole, chloramphenicol (AP-NA-TS-C) and 2 strains were resistant to ampicillin, nalidixic acid, tetracycline, chloramphenicol (AP-NA-T-C). One (1) strain of $V$. parahaemolyticus isolates was resistant to AP-NA-T. However, of the $41 \mathrm{~V}$. cholerae isolates showing drug resistance to at least one antibiotic, 2 were found to be resistant to ampicillin, nalidixic acid, tetracycline, and chloramphenicol (AP-NA-T-
C) which were found to be $V$. cholerae O1. All of the $V$. vulnificus isolates were susceptible to the ten antibiotics. The 36 isolates found to be resistant to at least 2 drugs were confirmed using API® Identification Kit 20E (BioMerieux®) (Table 4).

Table 3. Antimicrobial resistance profile of pathogenic vibrios isolated from mussels in Bacoor Bay, Cavite.

\begin{tabular}{|c|c|c|c|c|c|c|c|c|c|}
\hline \multirow{2}{*}{\multicolumn{5}{|c|}{ Antimicrobial resistance profile }} & \multicolumn{5}{|c|}{ Number of strains showing profile } \\
\hline & & & & & \multirow{2}{*}{$\begin{array}{c}\text { VA } \\
0\end{array}$} & \multirow{2}{*}{$\begin{array}{c}\text { VC } \\
0\end{array}$} & \multirow{2}{*}{$\begin{array}{c}\text { VP } \\
1\end{array}$} & \multirow{2}{*}{$\frac{\mathbf{V V}}{0}$} & \multirow{2}{*}{$\begin{array}{c}\begin{array}{c}\text { other } \\
\text { vibrios }\end{array} \\
0\end{array}$} \\
\hline $\mathrm{NE}$ & NA & TS & $\mathrm{T}$ & $S$ & & & & & \\
\hline AP & NA & TS & $\mathrm{T}$ & C & 1 & 0 & 0 & 0 & 2 \\
\hline AP & NA & TS & CIP & S & 1 & 0 & 0 & 0 & 0 \\
\hline $\mathrm{AP}$ & NA & TS & C & & 1 & 1 & 0 & 0 & 1 \\
\hline $\mathrm{AP}$ & NA & $\mathrm{T}$ & C & & 1 & 2 & 0 & 0 & 0 \\
\hline $\mathrm{AP}$ & NA & $\mathrm{T}$ & & & 3 & 3 & 1 & 0 & 3 \\
\hline $\mathrm{AP}$ & TS & $\mathrm{T}$ & & & 1 & 2 & 0 & 0 & 1 \\
\hline $\mathrm{AP}$ & TS & C & & & 0 & 0 & 1 & 0 & 1 \\
\hline $\mathrm{AP}$ & TS & & & & 2 & 4 & 3 & 0 & 7 \\
\hline $\mathrm{AP}$ & GM & & & & 2 & 0 & 0 & 0 & 0 \\
\hline $\mathrm{AP}$ & NA & & & & 1 & 2 & 0 & 0 & 0 \\
\hline CIP & TS & & & & 0 & 1 & 0 & 0 & 0 \\
\hline NA & $\mathrm{T}$ & & & & 0 & 1 & 1 & 0 & 0 \\
\hline NA & TS & & & & 0 & 0 & 0 & 0 & 1 \\
\hline $\mathrm{AP}$ & & & & & 28 & 17 & 22 & 0 & 21 \\
\hline C & & & & & 0 & 0 & 1 & 0 & 1 \\
\hline CIP & & & & & 2 & 0 & 0 & 0 & 1 \\
\hline NA & & & & & 4 & 2 & 0 & 0 & 11 \\
\hline S & & & & & 1 & 1 & 1 & 0 & 2 \\
\hline $\mathrm{T}$ & & & & & 1 & 3 & 4 & 0 & 4 \\
\hline TS & & & & & 0 & 2 & 1 & 0 & 3 \\
\hline $\begin{array}{l}\text { Susce } \\
\text { antibi }\end{array}$ & $\begin{array}{l}\text { ible/Ir } \\
\text { ics tes }\end{array}$ & rmec & & & 26 & 12 & 13 & 6 & 28 \\
\hline
\end{tabular}

$\overline{\text { VA - V. alginolyticus; VC - V. cholerae; VP - V. parahaemolyticus; VV - V. }}$ vulnificus

NE - neomycin; AP - ampicillin; NA - nalidixic acid; TS - co-trimoxazole; T tetracycline; C - chloramphenicol; CIP - ciprofloxacin; S - streptomycin 
Table 4. Confirmatory identification of twenty six pathogenic vibrios showing resistance to at least two drugs using API® Identification Kit 20E (BioMerieux $\left.{ }^{\circledR}\right)$.

\begin{tabular}{|c|c|c|c|}
\hline \multirow[b]{2}{*}{ Tests } & \multicolumn{3}{|c|}{ Number of Positive Strains (\%) } \\
\hline & $\begin{array}{c}\text { Vibrio } \\
\text { alginolyticus } \\
\mathrm{n}=13\end{array}$ & $\begin{array}{c}\text { Vibrio } \\
\text { cholerae } \\
\mathrm{n}=16\end{array}$ & $\begin{array}{c}\text { Vibrio } \\
\text { parahaemolyticus } \\
\mathrm{n}=7\end{array}$ \\
\hline$\beta$-galactosidase & $13(100 \%)$ & $16(100 \%)$ & $7(100 \%)$ \\
\hline Arginine dihydrolase & $13(100 \%)$ & $16(100 \%)$ & $7(100 \%)$ \\
\hline Lysine decarboxylase & $13(100 \%)$ & $16(100 \%)$ & $7(100 \%)$ \\
\hline Ornithine decarboxylase & $13(100 \%)$ & $16(100 \%)$ & $7(100 \%)$ \\
\hline Citrate utilization & $11(85 \%)$ & $15(94 \%)$ & $7(100 \%)$ \\
\hline $\mathrm{H}_{2} \mathrm{~S}$ production & $13(100 \%)$ & $16(100 \%)$ & $7(100 \%)$ \\
\hline Urease & $13(100 \%)$ & $16(100 \%)$ & $7(100 \%)$ \\
\hline Tryptophan deaminase & $13(100 \%)$ & $16(100 \%)$ & $7(100 \%)$ \\
\hline Indole production & $13(100 \%)$ & $16(100 \%)$ & $7(100 \%)$ \\
\hline Acetoin production & $13(100 \%)$ & $16(100 \%)$ & $7(100 \%)$ \\
\hline Gelatinase & $13(100 \%)$ & $16(100 \%)$ & $7(100 \%)$ \\
\hline O/F Glucose & $13(100 \%)$ & $16(100 \%)$ & $7(100 \%)$ \\
\hline O/F Mannose & $13(100 \%)$ & $16(100 \%)$ & $7(100 \%)$ \\
\hline $\mathrm{O} / \mathrm{F}$ Inositol & $13(100 \%)$ & $16(100 \%)$ & $7(100 \%)$ \\
\hline O/F Sorbitol & $13(100 \%)$ & $16(100 \%)$ & $7(100 \%)$ \\
\hline O/F Rhamnose & $13(100 \%)$ & $16(100 \%)$ & $7(100 \%)$ \\
\hline O/F Saccharose & $13(100 \%)$ & $16(100 \%)$ & $7(100 \%)$ \\
\hline O/F Melibiose & $13(100 \%)$ & $16(100 \%)$ & $7(100 \%)$ \\
\hline $\mathrm{O} / \mathrm{F}$ Amygdalin & $13(100 \%)$ & $16(100 \%)$ & $7(100 \%)$ \\
\hline $\mathrm{O} / \mathrm{F}$ Arabinose & $13(100 \%)$ & $16(100 \%)$ & $7(100 \%)$ \\
\hline
\end{tabular}

$\mathrm{O} / \mathrm{F}$ - Oxidation/Fermentation

\section{Discussion}

Bacoor Bay is one of the shellfish-farming sites in Cavite province and the major source of mussels, oysters and crustaceans for the nearby municipalities. Families living within and along the bay continue to increase in number. Hence, poor sanitation of the people in these areas remains to be the perennial problem of the municipal government. Since environmental sanitation is a potential health risk, the study focused on the investigation of pathogenic vibrios and their resistance pattern to antimicrobial agents.

Shellfishes have been reported to concentrate vibrios 100-fold compared with the amount found in the surrounding waters. ${ }^{15}$ Our results were in accordance with these observations. All of the samples $(n=90)$ were positive to vibrios using the direct plating method in TCBS. Variation in total vibrios during rainy months was observed ranging from $1.6 \times 10^{4} \mathrm{cfu} / \mathrm{g}$ in July 2009 to $1.3 \times 10^{6} \mathrm{cfu} / \mathrm{g}$ in August 2009. A study has shown to correlate density of vibrios to seasons wherein the lowest numbers of vibrios are found in rainy months whereas the highest counts can be observed in dry months. ${ }^{16}$ However, our results showed that the density of pathogenic vibrios was found to be high in rainy months. This high density can be attributed to the typhoons encountered and the release of effluents during rainy season. Much of the effluents are drained from industrial firms to Imus River that discharges them to the bay near site 1 . Since vibrios are alkalophiles, optimum $\mathrm{pH}$ is 8.5-8.6, their survival is favored ${ }^{1}$. An increase in $\mathrm{pH}$ particularly in site 1 can be observed and attributed to this. The abundance of vibrios was also affected by the water temperature, salinity and $\mathrm{pH}$. Statistical analysis revealed that the occurrence of vibrios can be predicted by these variables. These results concur from the previous ecological studies which reported success in the isolation of $V$. cholerae $\mathrm{O} 1$ during periods of warmer water temperatures. ${ }^{16}$ Of the pathogenic vibrios isolated, $V$. alginolyticus was the most predominant followed by $V$. cholerae and $V$. parahaemolyticus. Vibrio vulnificus was least detected.

Epidemiological surveillance of antimicrobial resistance is very important for empiric treatment of infections and in preventing the spread of antimicrobial resistant pathogenic vibrios. Our results revealed antibiotic resistance in vibrio isolates. The resistance patterns detected varied between one to five drugs respectively with all isolates being resistant to ampicillin-nalidixic acid. Forty one (41) V. cholerae isolates revealed drug resistance to at least one drug and surprisingly, two isolates having resistance to four antibiotics were $V$. cholerae $\mathrm{O} 1$ serotype. These results were in accordance to other studies wherein vibrios isolated from shrimp farming environments and sea foods were resistant to ampicillin, ${ }^{11,17} \quad$ tetracycline, ${ }^{17}$ lincomycin, ${ }^{18}$ chlortetracycline $^{19}$ and erythromycin. ${ }^{19}$ Resistance to ampicillin, tetracycline, nalidixic acid and erythromycin were also seen in $V$. cholerae isolated from patients. ${ }^{20}$ Similarly, vibrios with multiple drug resistance to ampicillin, cefuroxime, amikacin, kanamycin and trimethoprim among fifty one pathogenic Vibrio spp. isolated from silver sea bream (Sparus sarba) were observed and this was due to uncontrolled use of antibiotics in the environment. ${ }^{21}$ These observed differences may be due to the fact that first generation antibiotics including ampicillin, chloramphenicol and tetracycline have been thoroughly abused in marine environment. ${ }^{22}$ Resistant strains may have found their way in bays harboring these shellfishes because sewage is sometimes discharged into bodies of water without any form of treatment. The multidrug resistant pathogenic vibrios were isolated during the first week of October when typhoons Ondoy and Pepeng greatly flooded the area. This incident resulted to an increased discharge of black waters into the bay area.

The isolated $V$. alginolyticus, $V$. cholerae, $V$. parahaemolyticus and Vibrio vulnificus in mussels of Bacoor Cavite can be predicted using the environmental parameters such as salinity, temperature and $\mathrm{pH}$. Majority of these isolates were found to be resistant to ampicillin. The results indicate that potentially pathogenic vibrios can pose a health hazard to mussel consumers in Bacoor, Cavite and its nearby towns.

The isolation of potentially pathogenic vibrios from mussels is a health risk for people consuming raw seafoods. Therefore, a long term monitoring program should be included in the development plans of the municipal government. The relocation of the people living within and 
along the bay can greatly reduce the transmission of vibriosis and cholera in the said vicinity.

\section{Acknowledgment}

This research was supported by the De La Salle University Dasmariñas Faculty Research Grant (UFRO 0263-S-09).

\section{References}

1. Forbes B, Sahm D, Weissfeld A. Bailey and Scott's Diagnostic microbiology, 11 ${ }^{\text {th }}$ ed. Singapore:Elsevier Science; 2002.

2. Field Health Services Information System. Ten leading cause of morbidity in the Philippines. Division of Public Health Surveillance and Informatics Division, National Epidemiology Center, Department of Health. 2008.

3. Wittman RJ, Flick GJ. Microbial contamination of shellfish: prevalence, risk to human health, and control strategies. Annu Rev Public Health. 1995; 16:123-40.

4. Department of Health. Cholera outbreaks in the Philippines. 2008.

5. Colwell RR. Global climate and infectious disease: the cholera paradigm. Science. 1996; 274(5295):2025-31.

6. Oliver J. Vibrio Vulnificus. In: Thompson F, Austin B, Swings J., eds. The biology of vibrios. Washington D.C.:ASM Press; 2006. pp. 349-366.

7. Cabello FC. Heavy use of prophylactic antibiotics in aquaculture: a growing problem for human and animal health and for the environment. Environ Microbiol. 2006; 8:1137-44.

8. Zanetti S, Spanu T, Deriu A, Romano L, Sechi LA, Fadda G. In vitro susceptibility of Vibrio spp. isolated from the environment. Int $\mathrm{J}$ Antimicrob Agents. 2001;17(5):407-9.

9. Sack D, Lyke C, Mclaughlin C, Suwanvanichkij V., eds. Antimicrobial resistance in shigellosis, cholera and campylobacteriosis. WHO/CDS/CSR/DRS/2001.8. 2001.

10. Kobari K, Takakura I, Nakatomi M. Antibiotic resistant strains Of El Tor Vibrio in the Philippines and the use of furalazine for chemotherapy. In: Sack D, Lyke C, Mclaughlin C, Suwanvanichkij V, eds. Antimicrobial resistance in shigellosis, cholera and campylobacteriosis. WHO/CDS/CSR/DRS/2001.8 2001. p. 10.
11. Brooks GF, Caroll KC, Butel JS, Morse SA, eds. In: Jawetz, Melnick, \&Adelberg's Medical Microbiology, 24 $4^{\text {th }}$ ed. USA:The McGraw-Hill Companies, Inc.; 2007.

12. Mcphee S, Papadakis M. Current medical diagnosis and treatment, $46^{\text {th }}$ ed. USA:McGraw-Hill Co. Inc.; 2007.

13. De Paola Jr A, Kaysner C. Vibrio Cholerae, V. Parahaemolyticus, V. Vulnificus, and other Vibrio spp. Bacteriological Analytical Manual, $8^{\text {th }}$ ed. FDA. 2004.

14. Clinical and Laboratory Standards Institute. Performance standards for antimicrobial susceptibility testing: sixteenth informational supplement. CLSI document M100-S16; Wayne, Pa: CLSI; 2006.

15. De Paola Jr A, Nordstrom J, Bowers J, Wells J, Cook D. Seasonal abundance of total and pathogenic Vibrio parahaemolyticus in Alabama oysters. Appl Environ Microbiol. 2003;69(3):1521-6.

16. Deepanjali A, Sanath Kumar H, Karunasagar I, Karunasagar I. Seasonal variation in abundance of total and pathogenic Vibrio parahaemolyticus bacteria in oysters along southwest coast of India. Appl Environ Microbiol. 2005;71(7):3575-80.

17. Reboucas RH, de Sousa OV, Lima AS, Vasconcelos FR, de Carvalho PB, Vieira RH. Antimicrobial resistance profile of Vibrio species isolated from marine shrimp farming environments (Litopenaeus vannamei) at Ceara, Brazil. Environ. Res. 2011; 111(1):21-4.

18. Ottaviani D, Bacchiocchi I, Masini L, et al. Antimicrobial susceptibility of potentially pathogenic halophilic vibrios isolated from seafood. Int J Antimicrob Agents. 2001;18(2):135-40.

19. Vaseeharan B, Ramasamy P, Murugan T, Chen JC. In vitro susceptibility of antibiotics against Vibrio spp. and Aeromonas spp. isolated from Penaeus monodon hatcheries and ponds. Int J Antimicrob Agents. 2005;26(4):285-91.

20. Urassa WK, Mhando YB, Mhalu FS, Mjonga SJ. Antimicrobial susceptibility pattern of Vibrio cholerae O1 strains during two cholera outbreak in Dar Es Salaam, Tanzania. East Afr Med J. 2000; 77(7):350-3.

21. Li J, Yie J, Foo R, Ling J, Xu H, Norman Y. Antibiotic resistance and plasmid profiles of Vibrio isolates from cultured silver sea bream, Sparus salba. Mar Pollut Bull. 2003; 39(1-12):45-9.

22. Adeleye IA. Conjugal transferability of multiple antibiotic resistances in three genera of Enterobacteriaceae in Nigeria. J Diarrhoeal Dis Res. 1992;10(2):93-6.

\section{Acta Medica Philippina}

THE NATIONALHEALTH SCIENCE JOURNAE

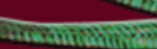

\section{Acta is now accepting membership \\ Privileges of members:}

- Allows you to submit articles for possible publication

- Have access to all the articles in the website (archives included) which can be downloaded and printed in pdf format

- Advertise your products/services in the available spaces of the website (for approval of the Editor-in-chief)

For details, please visit our website at www.actamedicaphilippina com ph or e-mail us at businessmanager@actamedicaphilippina.com.ph for any questions or queries. 